\title{
The influence of zeolites' surface modification on sorption, structural and textural features
}

\author{
B. MUIR ${ }^{1 *}$, T. BAJDA ${ }^{1}$
}

${ }^{1}$ AGH University of Science and Technology, Faculty of Geology, Geophysics and Environmental Protection, al. A. Mickiewicza 30, 30-059 Kraków, Poland

(*correspondance: basia.muir@gmail.com)

\section{Methods}

The main objective of the study was to investigate and compare the features of synthetic zeolite Na-P1, and its modifications with quaternary ammonium salts. Materials were studied by X-ray diffraction (XRD), Fourier-transform infrared spectroscopy (FTIR) and scanning electron microscopy (SEM). To understand the structure-property relationships of selected zeolites and organo-zeolites, a textural study (porosity, surface area, and mean pore size) and thermogravimetric analysis were conducted.

\section{Results}

A novel procedure using FTIR was developed to determine the quantity of the adsorbed surfactant on the surface of the zeolites. The results showed that the modification improves the sorption properties in terms of organic compounds and anions, however significantly reverses the textural and structural properties (Table 1).

\begin{tabular}{cccc}
\hline & P & P 12 & P 18 \\
\hline$S_{\text {BET }}\left[\mathrm{m}^{2} / \mathrm{g}\right]$ & 74.91 & 59.51 & 20.40 \\
\hline$V_{\text {tot }}^{0.99}\left[\mathrm{~cm}^{3} / \mathrm{g}\right]$ & 0.225 & 0.256 & 0.184 \\
\hline$V_{\text {mic }}^{T}\left[\mathrm{~cm}^{3} / \mathrm{g}\right]$ & 0.030 & 0.023 & 0.012 \\
\hline$V_{\text {mes }}^{\text {BJH }}\left[\mathrm{cm}^{3} / \mathrm{g}\right]$ & 0.161 & 0.175 & 0.125 \\
\hline$V_{\text {mac }}\left[\mathrm{cm}^{3} / \mathrm{g}\right]$ & 0.034 & 0.058 & 0.047 \\
\hline
\end{tabular}

Table 1: Porous texture parameters. P - synthetic zeolite NaP1; P 12, P 18 - modifications with DDTMA, and ODTMA.

The carbon chain length of the surfactants has an impact on the texture parameters. With an increasing chain length all the texture parameters decrease. With a decreasing chain length the surfactants' chains adopted a more disorderly conformations.

\section{Acknowledgements}

We gratefully acknowledge the support of Foundation for Polish Science having provided Grant No. POIR.04.04.0000-14E6/18. 